\title{
Title: Expression and content of the LC3B protein in gastric cancers, relationship to MTOR, AMPK expression, clinical and morphological parameters, and the tumor response to neoadjuvant chemotherapy
}

Liudmila V. Spirina

Tomsk Cancer Research Institute

Alexandra V. Avgustinovich

Tomsk Cancer Research Institute

Olga Bakina ( $\Delta$ ovbakina@ispms.tsc.ru )

Institute of Strength Physics and Materials Science

Sergey G. Afanas'ev

Tomsk Cancer Research Institute

Maxim Yu. Volkov

Tomsk Cancer Research Institute

\section{Research Article}

Keywords: gastric cancer, LC3B, mTOR, AMPK, NACT

Posted Date: March 1st, 2021

DOI: https://doi.org/10.21203/rs.3.rs-236071/v1

License: (a) This work is licensed under a Creative Commons Attribution 4.0 International License.

Read Full License 


\section{Abstract}

Background. Autophagy plays a dual role in oncogenesis processes. On the one hand, increasing the cell's resistance to oncogenic factors, and on the other hand, participating in the processes of tumor progression and the formation of resistance to antitumor treatment. It has been shown that autophagy correlates with the aggressive course of the disease and its poor prognosis. The molecular cascades that regulate autophagy are numerous and varied and play a role in tumorigenesis that has not yet been studied.

The study aimed to study the expression of LC3B, mTOR, AMPK, the content of the LC3B protein in gastric cancer tissue, and its relationship with disease progression, and the response to anti-cancer therapy.

Material and methods. The study included 34 patients with morphologically verified gastric cancer. All patients were hospitalized in the Department of Abdominal Oncology of the TNIMTs Research Institute of Oncology. All patients had FLOT neoadjunvant chemotherapy (NACT) (fluorouracil, leucovorin, oxaliplatin, and docetaxel) followed the gastrectomy. The response to the combined treatment of patients was evaluated according to the RECIST 1.1 criteria.

The study's material was the non-transformed and tumor tissues obtained during diagnostic video gastroscopy in patients before the start of combined treatment and after surgical treatment, frozen after collection and stored at $\mathrm{t}-80^{\circ} \mathrm{C}$. The expression of LC3B, mTOR, AMPK was determined by real-time PCR, the LC3B protein level - using the Western Blotting method.

Results and their discussion. The mRNA level and the content of the LC3B protein are associated with the size of the tumor, damage to regional lymph nodes (spread of the disease), and the presence of cricoid cells. The AMPK mRNA level increased in patients with the $\mathrm{T}_{4} \mathrm{~N}_{0-2} \mathrm{M}_{0}$ stage in 37.7 and 7.33 times, respectively, compared with patients with the $\mathrm{T}_{2} \mathrm{~N}_{0} \mathrm{M}_{0}$ and $\mathrm{T}_{3} \mathrm{~N}_{0-1} \mathrm{M}_{0}$ stages. The opposite character in mTOR, AMPK changes in the GCs before anti-cancer therapy is noted. At the same time, the local prevalence of the tumor and the lesion of regional lymph nodes were associated with a decrease in mTOR mRNA level.

A decrease in mTOR expression is accompanied by an increase in AMPK expression in a gastric tumor. It is associated, first of all, with the clinical and morphological parameters of the primary process. mTOR expression is reduced in patients with a higher local prevalence of the process; in contrast, AMPK grows with tumor size.

There is an increase in the LC3B expression, which, probably, can determine the response to therapy. As a result of the study, an increase in LC3B mRNA before the start of treatment and the concentration of autophagy protein after NACT with a decrease in therapy effectiveness was recorded. An increase in the protein level in patients with partial regression and stabilization of the tumor process by 3.65 and 5.78 times compared with patients with complete tumor regression was noted. 
Conclusion. The development of the disease and the prediction of anticancer therapy's effectiveness is directly related to the expression level of LC3B, MTOR, and AMPK. The following relationship was revealed: a decrease in mTOR expression and an increase in the level of mRNA and protein LC3B, AMPK expression combined with the progression of the disease in the form of the development of distant metastases, as well as the predicted future low effectiveness of NACT.

\section{Introduction}

The gastric cancer (GC) is one of the most prevalent malignant types in the world with a poorly understood carcinogenesis at the molecular and genetic level [Matsuoka T, 2018]. GC is the most common and the most lethal cancer, presents the urgent global problem [Johnston FM, 2019]. Multiple mechanisms are known to be participating in the GC initiation and progression [De Re 2018]. The key and little studied pathway in oncogenesis is associated with the autophagy [Eslami M, 2019]. It is believed that the activation of "self-eating" can be initiated by Helicobacter pylori (or H. pylori) infection, which promotes tumourigenesis of the gastric mucosa [Ishaq S, 2015] and protects cells from apoptosis [Gao Y, 2019].

Autophagy is associated with the processes of cell survival, its death. It is a vital intracellular homeostatic process through which defective proteins and organelles are degraded and recycled under starvation, hypoxia or other specific cellular stress conditions [Cao 2019]. It is known to affect the metastatic processes of gastric cancer by acting on a wide range of molecular targets, including degradation of the extracellular matrix, the development of the epithelial-mesenchymal transition, tumor angiogenesis, and modification of the tumor microenvironment [Yoshii SR, et al. 2017; Cao Y, et al., 2019].

It plays a dual role in oncogenesis processes [Eslami M, 2019]. On the one hand, it increases the cell's resistance to oncogenic factors; on the other hand, it participates in the processes of tumor progression and the formation of resistance to antitumor treatment [Qiu J, 2020; Gao Y, 2019]. It has been shown the autophagy initiation correlates with the aggressive course of the disease and its poor prognosis [Spirina 2020].

The proteins associated with autophagy include a complex of proteins that play a decisive role at all stages of autophagosome development, for example, the autophagy-associated protein Atg13 (ULK1), Beclin-1, vacuolar protein sorting 34 (VPS34), VPS15, Atg14 and associated with microtubules protein 1A / 1B-light chain 3- (LC3B). The latter is a structural protein of autophagosome membranes and is widely used as a marker of this process. High levels of LC3B are found in gastric cancer cells [Giatromanolaki A, 2019] and can predict the disease's outcome [Kim JS, 2019].

The multiple study molecular cascades regulate and control the autophagy. Research efforts are focused on the of serine/threonine protein kinases AMP-activated protein kinase, (AMPK) rapamycin-inhibited kinase of mammals (mTOR) [Alers S., 2012]. In gastric cancer development, these molecular parameters play an ambiguous role, which is still not fully understood. It is known that the activation of protein kinase AMPK can be accompanied by the development of an antitumor effect, which is accompanied by 
an increase in the sensitivity of the tumor to treatment [Luan $M, 2020]$. There is also evidence that AMPK is associated with the development of resistance to chemotherapy treatment in gastric cancer [Park JB 2018]. The role of mTOR kinase is also diverse. It integrates various signaling pathways, including AKT/mTOR, activated under the influence of growth factors and mitogens [Xiao F, 2020]. It is believed that mTOR activation inhibits the development of the self-eating process and is accompanied by protein synthesis processes [Tapia, 0. 2014]. In contrast to the kinase AMPK, associated with the regulation of energy metabolism and triggering the process of protein degradation [Zadra G, 2015].

The list of molecular biomarkers that can be used for prognostic purposes varies annually [Machlowska $\mathrm{J}, 2018$ ]. Currently, there is data on markers predicting the effect of neoadjuvant therapy in GC. It is known that the expression level of the AKT gene can predict the impact of chemotherapy in GC [Murakami D, 2007; Tapia 0, 2014]. It is believed that a complex of molecular indicators is involved both in anti-cancer process and tumourigenesis [Sasaki T, 2014]. The AKT/mTOR signaling cascade triggers sensitivity to treatment [Spirina 2018], and autophagy [Park JB 2018]. It is known the effect of therapy based on 5fluorouracil and cisplatin is associated with changes in the expression profiles of the intracellular signaling cascades components (the AKT/mTOR signaling cascade and autophagy markers) [Qi W, 2020], and can predict the effect of the anti-cancer treatment [Peng R, 2020]. In general, the role of biological indicators associated with autophagy in GC progression and response to therapy is still unclear.

The study aimed to study the expression and content of LC3B and the level of mTOR and AMPK mRNA in gastric cancer tissue in connection with the disease's prevalence, and the effectiveness of anticancer therapy.

\section{Materials And Methods}

The Local Committee of Medical Ethics in Cancer Research Institute, Tomsk National Research Medical Center of the Russian Academy of Sciences, approved this work, Minute No. 5, dated April 24, 2019. The study included 34 patients with GC who received 3 courses of FLOT neoadjunvant chemotherapy (NACT) (fluorouracil, leucovorin, oxaliplatin, and docetaxel). The patients admitted to the Cancer Research Institute, Tomsk National Research Center, Russian Academy of Medical Sciences, Tomsk, Russian Federation. Tumor response to therapy was evaluated according to RECIST 1.1 criteria. All patients underwent radical gastrectomy. Four patients had a complete response, partial response was detected in 8 patients, stable disease - in 16 people and progressive disease - in 6 ones. $T_{2} N_{0-1} M_{0}$ stage was observed in 5 patients; $T_{3} N_{0-1} M_{0}$ - in 15 people, and $T_{4} N_{0-2} M_{0}$ - in 14 ones. 13 patients had no affected lymph nodes (T2-3NOM0 stage); lymph node metastases (LNMs) and $\mathrm{T}_{2-3} \mathrm{~N}_{1} \mathrm{M}_{0}$ stage -12 ones; $\mathrm{T}_{3-}$ ${ }_{4} \mathrm{~N}_{2} \mathrm{M}_{0}$ stage was detected in 9 ones. Highly differentiated adenocarcinoma was verified in 4 people, moderately differentiated - in 6 patients; low - in 16; the signet ring cell carcinoma was noted in 8 people.

Diagnosis was verified on the basis of biopsy results. The Local Committee for Medical Ethics approved the study, and all patients provided written informed consent. All procedures involving patients were 
carried out in accordance with the Protocol of the Declaration of Helsinki on Human Rights (1964).

Biopsy post-operative samples of normal gastric, tumor tissues were used for investigation. Specimens were reviewed separately by two independent pathologists. Tissues were frozen and stored at $\mathrm{t}-80^{\circ} \mathrm{C}$

RNA extraction. The tumor samples were incubated in RNAlater solution (Ambion, USA) for 24-hours at + $4{ }^{\circ} \mathrm{C}$ and then stored at $-80 \mathrm{oC}$. Total RNA was extracted using RNeasy Mini Kit (Qiagen).

RT-qPCR was performed according to [Pfaffl MW]. PCR was conducted in $25 \mu$ reaction volumes containing $12.5 \mu$ l BioMaster HS-qPCR SYBR Blue (2X) ("Biolabmix" Russia) and 300 nanoM of each primers: LC3B: F 5'- CCCAAACCGCAGACACAT-3', R 5'-ATCCCACCAGCCAGCAC-3'; m-TOR: F 5'CCAAAGGCAACAAGCGAT-3', R 5'- TTCACCAAACCGTCTCCAA -3'; AMPK: F 5'AAGATGTCCATTGGATGCACT-3', R 5'-TGAGGTGTTGAGGAACCAGAT-3'; GAPDH: F 5'GGAAGTCAGGTGGAGCGA-3', R 5'-GCAACAATATCCACTTTACCAGA-3'.

A pre-incubation at $95^{\circ} \mathrm{C}$ for 10 min was to activate the Hot Start DNA polymerase and denature DNA, and was followed by 45 amplification cycles of $95^{\circ} \mathrm{C}$ denaturation at 950 for $10 \mathrm{sec}, 60^{\circ} \mathrm{C}$ annealing at 600 for $20 \mathrm{sec}$ (iCycler iQ ${ }^{\mathrm{TM}}$, BioRad).

The fold changes were calculated by $\Delta \Delta \mathrm{Ct}$ method (the total $\Delta \Delta \mathrm{Ct}=$ fold of cancerous/normal tissue gene level), using normal tissue. A ratio of specific mRNA/ GADPH (GADPH as a respective control) amplification was then calculated.

Determination of LC3B content. Electrophoresis SDS-PAGE (Laemmli) was used [Laemmli UK, 1970]. The protein was transferred to 0.2-/xm pore-sized PVDF membrane (GE Healthcare, UK), either at $150 \mathrm{~mA}$ or $100 \mathrm{~V}$ for $1 \mathrm{~h}$ by using a Bio-Rad Mini Trans- Blot electrophoresis cell. The membrane was incubated in a 1:2500 dilution of monoclonal mouse anti-human LC3B (Affinity Biosciences, USA) at $4{ }^{\circ} \mathrm{C}$ overnight.

PVDF samples were incubated in Amersham ECL western blotting detection analysis system (Amersham, USA). The results were standardized using the beta-actin expression in a sample and were expressed in percentages to the protein content in non-transformed tissues. The level of protein in normal gastric tissue was indicated as $100 \%$.

Statistical analysis. Statistical analysis was performed using SPSS 19.0 software. Data were expressed as median and ranges. Mann-Whitney test was used for comparing differences in mean values. nonparametric one-way ANOVA on ranks was carried out for testing whether samples originate from the same distribution, which is used for comparing two or more independent samples of equal or different sample sizes. Nonparametric correlation analysis was performed and the Spearmen coefficient was calculated.

\section{Results And Discussion}


The expression of $\angle C 3 B, M T O R, A M P K$, and the content of $\angle C 3 B$ protein in gastric cancer tissue depends on the disease's clinical and morphological parameters. We found the LC3B protein mRNA level before the start of neoadjuvant chemotherapy (NACT) elevated with an increase in tumor size and the disease spreading to the regional lymph nodes and increasing the number of affected lymph nodes (Table 1). When studying the mTOR and AMPK expression in GC tissue in connection with the clinical and morphological parameters of the disease examined before treatment, their relationship with the tumor size and the prevalence of the disease was recorded. The AMPK mRNA level increased in patients with the $T_{4} \mathrm{~N}_{0-2} \mathrm{M}_{0}$ stage 37.7 and 7.33 times, respectively, compared with patients with the disease $T_{2} N_{0} M_{0}$ and $T_{3} N_{0-1} M_{0}$ stages. Simultaneously, the prevalence of the disease and the defeat of regional lymph nodes were associated with a decrease in the MTOR mRNA level. It is noted that the content of the LC3B protein, assessed after NACT, is related to the size of the tumor, lesions of regional lymph nodes (spread of the disease), and the presence of signet ring cell carcinoma. All patients did not have distant metastases.

The relationship between LC3B expression and its protein content after NACT with the GC grade and histological type was revealed. In patients with the presence of the signet ring cell, there is a decrease in the LC3B gene expression by 8.47 times in the biopsies, and the level of the autophagy protein by 4.7 times after NACT compared with patients with low-differentiated adenocarcinoma (Table 2). At the same time, there is evidence that this indicator's expression is associated with the grade of the tumor. However, mTOR and AMPK mRNA levels were not related to the GC grade and the presence of signet ring cell.

It should be noted that there is a correlation between the level of LC3B mRNA before treatment and the protein content after NACT, measured by the Western Blotting analysis $(r=0.43 ; p=0.013)$. A negative relationship was also revealed between the studied parameter and mTOR expression $(r=-0.38 ; p=0.03)$ (Figure 1).

Changes in the expression of $\angle C 3 B$, mTOR, AMPK in tumor tissue after the NACT. After treatment, there is an increase in the mRNA level of the LC3B gene by 5.94 times compared with that before therapy (Figure 2). Simultaneously, the expression of autophagy regulators, kinases mTOR, AMPK after chemotherapeutic treatment did not change from the level of those before the start of treatment.

Relationship of LC3B, mTOR, AMPK expression, and LC3B protein content in GC tissue with the effectiveness of NACT. LC3B mRNA levels in GCs before therapy were not associated with response to treatment. However, as a result of the study, a relationship was found between the LC3B content after NACT and therapy's effectiveness in the tumor tissue (Figure 3). An increase in the protein level in patients with partial response and stable disease by 3.65 and 5.78 times compared with patients with complete response was noted. The data obtained indicate the role of autophagy in the treatment resistance initiation.

Considering the above facts, there is a question about the presence of predictive molecular markers that determine the behavior of the tumor, which can predict the development of autophagy. These indicators 
include the expression of mTOR and AMPK. Table 3 presents data on the relationship between the expression of the studied parameters with the effectiveness of therapy. A decrease in mTOR level before treatment in a tumor was recorded in patients with a reduction in response to treatment, in a series of complete tumor regression, partial stabilization of the disease, and progression. In this case, the expression of AMPK had an undulating character of changes. Simultaneously, the most pronounced differences, an 8, 5-fold increase in the indicator, were observed in patients with disease progression compared with patients with partial regression.

Discussion. It is known that a high content of the LC3B protein of gastric tumors is one of the markers of the disease [Giatromanolaki A, 2019] and can predict the outcome of the disease [Kim JS, 2019]. This study showed that LC3B expression is associated with tumor size and disease prevalence. The aggravation of the pathological process, which includes poorly differentiated tumors and the presence of cricoid cells, was associated with an increase in LC3B mRNA level.

mTOR expression is reduced in patients with a higher prevalence of the disease and HER2 positive tumor status; in contrast, AMPK increases with tumor size.

At the same time, the presence of aggravating clinical factors, for example, the prevalence of the disease, the presence of cricoid cells, was associated with a low level of LC3B expression before the onset of NACT and a drop in the content of the corresponding protein after treatment, assessed by Western blotting in the operating material.

Also, during the treatment, an increase in the autophagosome protein gene LC3B expression was revealed. The revealed fact confirms the significance of the high content of LC3B associated with an unfavorable outcome of the disease and the development of resistance to therapy [Giatromanolaki A, 2019; Kim JS, 2019]. An increase in autophagy's protein content with a decrease in the effect of treatment was recorded. It is known that the impact of therapy based on 5-fluorouracil and cisplatin is associated with a change in the expression profiles of the components of intracellular signaling cascades, in particular, the AKT/mTOR signaling cascade and autophagy markers [Qi W, 2020], and can predict the effect of the treatment [Peng R, 2020].

Currently, there is scant information about markers that can predict the effect of neoadjuvant therapy in gastric cancer, to which the level of expression of the AKT gene [Murakami D, 2007; Tapia 0, 2014; Sasaki T, 2014; Spirina 2018], creating the sensitivity to treatment and directly involving the autophagy-related molecular mechanism [Park JB 2018].

Critical regulators of autophagy include AMPK and mTOR [Alers S., 2012; Tapia, 0. 2014; Zadra G, 2015]. The opposite changes in the AMPK expression in the GCs before the anti-tumor therapy is noted, predicting the tumor response to treatment. An increase in AMPK expression accompanies a decrease in mTOR expression. It is believed that the activation of protein kinase AMPK may influence the effectiveness of therapy [Luan M, 2020], including the development of resistance to chemotherapy treatment in gastric cancer [Park JB 2018]. 


\section{Conclusion}

The expression of LC3B, mTOR, AMPK, and the content of LC3B protein in gastric cancer tissue depends on the cancer spreading and affection of lymph nodes. The signet cell carcinoma has been associated with decreased expression and content of the LC3B protein.

Change in the LC3B expression in GC was found after the NACT. The relationship of LC3B, mTOR, AMPK expression, and LC3B protein content in GC tissue with the effectiveness of NACT was found.

Oncogenesis and prediction of anticancer therapy's effectiveness related to the LC3B, MTOR, and AMPK expression. The growth in LC3B mRNA level in the cancers after NACT was recorded. The study revealed a relationship between the response to the anti-cancer therapy, mTOR, AMPK expression in the tumor tissue before treatment, which predicts the effect of therapy. Besides, the LC3B protein content in GCs after treatment increased with a decrease in effect of NACT. We revealed the molecular features, associated with the prediction to anticancer therapy's effectiveness.

\section{Declarations}

Authorship contributions:

Study concepts/ review-analysis/ manuscript drafting and approved the final version: all authors Conflict of interests:

The authors declare that there are no conflicts of interest.

Funding: Determination of LC3B content was performed according to the Government research assignment for ISPMS SB RAS, project FWRW-2019-0033.

\section{References}

1. Alers S, Löffler AS, Wesselborg S, Stork B. Role of AMPK-mTOR-Ulk1/2 in the regulation of autophagy: cross talk, shortcuts, and feedbacks. Mol Cell Biol. 2012 Jan;32(1):2-11. doi: 10.1128/MCB.06159-11. Epub 2011 Oct 24. PMID: 22025673; PMCID: PMC3255710.

2. Cao Y, Luo Y, Zou J, Ouyang J, Cai Z, Zeng X, Ling H, Zeng T. Autophagy and its role in gastric cancer. Clin Chim Acta. 2019 Feb;489:10-20. doi: 10.1016/j.cca.2018.11.028. Epub 2018 Nov 22. PMID: 30472237.

3. Gao Y, Qi W, Liu S, Zhao S, Lv J, Qiu W. Acid-induced autophagy protects human gastric cancer cells from apoptosis by activating Erk1/2 pathway. Transl Cancer Res 2019;8(4):1560-1570. doi: $10.21037 /$ tcr.2019.07.42

4. Giatromanolaki A, Koukourakis MI, Georgiou I, Kouroupi M, Sivridis E. LC3A, LC3B and Beclin-1 Expression in Gastric Cancer. Anticancer Res. 2018 Dec;38(12):6827-6833. doi: 10.21873/anticanres.13056. Erratum in: Anticancer Res. 2019 Jan;39(1):527. PMID: 30504397. 
5. Ishaq S, Nunn L. Helicobacter pylori and gastric cancer: a state of the art review. Gastroenterol Hepatol Bed Bench. 2015 Spring;8(Suppl 1):S6-S14. PMID: $26171139 ;$ PMCID: PMC4495426.

6. Janser FA, Tschan MP, Langer R. The role of autophagy in HER2-targeted therapy. Swiss Med Wkly. 2019 Oct 27;149:w20138. doi: 10.4414/smw.2019.20138. PMID: 31656036.

7. Kim JS, Bae GE, Kim KH, et al. Prognostic Significance of LC3B and p62/SQSTM1 Expression in Gastric Adenocarcinoma. Anticancer Research. 2019 Dec;39(12):6711-6722. DOI: 10.21873/anticanres.13886.

8. Kim JS, Bae GE, Kim KH, Lee SI, Chung C, Lee D, Lee TH, Kwon IS, Yeo MK. Prognostic Significance of LC3B and p62/SQSTM1 Expression in Gastric Adenocarcinoma. Anticancer Res. 2019 Dec;39(12):6711-6722. doi: 10.21873/anticanres.13886. PMID: 31810936.

9. Laemmli UK. Cleavage of structural proteins during the assembly of the head of bacteriophage T4. Nature. 1970 Aug 15;227(5259):680-5. doi: 10.1038/227680a0. PMID: 5432063.

10. Li CJ, Liao WT, Wu MY, Chu PY. New Insights into the Role of Autophagy in Tumor Immune Microenvironment. Int J Mol Sci. 2017 Jul 19;18(7):1566. doi: 10.3390/ijms18071566. PMID: 28753959; PMCID: PMC5536054.

11. Luan M, Shi SS, Shi DB, et al. TIPRL, a Novel Tumor Suppressor, Suppresses Cell Migration, and Invasion Through Regulating AMPK/mTOR Signaling Pathway in Gastric Cancer. Front Oncol. 2020;10:1062. Published 2020 Jul 3. doi:10.3389/fonc.2020.01062

12. Murakami D, Tsujitani S, Osaki T, Saito H, Katano K, Tatebe S, Ikeguchi M. Expression of phosphorylated Akt (pAkt) in gastric carcinoma predicts prognosis and efficacy of chemotherapy //Gastric Cancer. 2007;10(1):45-51.

13. Park JB, Lee JS, Lee MS, Cha EY, Kim S, Sul JY. Corosolic acid reduces 5-FU chemoresistance in human gastric cancer cells by activating AMPK. Mol Med Rep. 2018;18(3):2880-2888. doi:10.3892/mmr.2018.9244

14. Pfaffl MW. A new mathematical model for relative quantification in real-time RT-PCR. Nucleic Acids Res. 2001 May 1;29(9):e45. doi: 10.1093/nar/29.9.e45. PMID: 11328886; PMCID: PMC55695

15. Peng R, Chen Y, Wei L, et al. Resistance to FGFR1-targeted therapy leads to autophagy via TAK1/AMPK activation in gastric cancer [published online ahead of print, $2020 \mathrm{Jul} 2$ ]. Gastric Cancer. 2020;10.1007/s10120-020-01088-y. doi:10.1007/s10120-020-01088-y

16. Qi W, Zhang Q. Gene's co-expression network and experimental validation of molecular markers associated with the drug resistance of gastric cancer Biomark Med. 2020;10.2217/bmm-2019-0504. doi:10.2217/bmm-2019-0504

17. Sasaki T, Kuniyasu H. Significance of AKT in gastric cancer (Review). Int J Oncol.2014 Dec;45(6):2187-92. doi: 10.3892/ijo.2014.2678.

18. Spirina L.V., Kondakova I.V., Tarasenko N.V., Slonimskaya E.M., Usynin E.A., Gorbunov A.K., Yurmazov Z.A., Chigevskaya S.Y. Targeting of the AKT/m-TOR Pathway: Biomarkers of Resistance to Cancer Therapy--邓AKT/m-TOR Pathway and Resistance to Cancer Therapy. Chinese Journal of Lung Cancer. 2018; 21. (1):63-66. 
19. Spirina LV, Avgustinovich AV, Afanas'ev SG, Cheremisina OV, Volkov MY, Choynzonov EL, Gorbunov AK, Usynin EA. Molecular Mechanism of Resistance to Chemotherapy in Gastric Cancers, the Role of Autophagy. Curr Drug Targets. 2020;21(7):713-721. doi: 10.2174/1389450120666191127113854. PMID: 31775598.

20. Spirina LV, Avgustinovich AV, Afanas'ev SG, Kondakova IV, Volkov MY, Dobrodeev AY, Boronkina Al. AKT/mTOR Signal Cascade and Expression of PD-1, PD-L1, and PD-L2 in Gastric Cancer. Bull Exp Biol Med. 2020 Nov;170(1):75-78. doi: 10.1007/s10517-020-05007-0. Epub 2020 Nov 24. PMID: 33231797.

21. Tapia O, Riquelme I, Leal P, Sandoval S, Aedo S, Weber H, Letelier P, Bellolio E, Villaseca M and Roa JC. The PI3K/AKT/mTOR pathway is activated in gastric cancer with potential prognostic and predictive significance. Virchows Arch.2014 Jul;465(1):25-33. doi: 10.1007/s00428-014-1588-4.

22. Tracey N, Creedon H, Kemp AJ, Culley J, Muir M, Klinowska T, Brunton VG. HO-1 drives autophagy as a mechanism of resistance against HER2-targeted therapies. Breast Cancer Res Treat. 2020 Feb;179(3):543-555. doi: 10.1007/s10549-019-05489-1. Epub 2019 Nov 8. PMID: 31705351; PMCID: PMC6997276.

23. Wang X, Wu WKK, Gao J, Li Z, Dong B, Lin X, Li Y, Li Y, Gong J, Qi C, Peng Z, Yu J, Shen L. Autophagy inhibition enhances PD-L1 expression in gastric cancer. J Exp Clin Cancer Res. 2019 Mar 29;38(1):140. doi: 10.1186/s13046-019-1148-5. PMID: 30925913; PMCID: PMC6440013.

24. Xiao F, Ouyang B, Zou J, Yang Y, Yi L, Yan H. Trim14 promotes autophagy and chemotherapy resistance of gastric cancer cells by regulating AMPK/mTOR pathway. Drug Dev Res. 2020;81(5):544-550. doi:10.1002/ddr.21650

25. Yoshii SR, Mizushima N. Monitoring and Measuring Autophagy. Int J Mol Sci. 2017 Aug 28;18(9):1865. doi: 10.3390/ijms18091865. PMID: 28846632; PMCID: PMC5618514.

26. Zadra G, Batista JL, Loda M. Dissecting the Dual Role of AMPK in Cancer: From Experimental to Human Studies. Mol Cancer Res. 2015 Jul;13(7):1059-72. doi: 10.1158/1541-7786.MCR-15-0068. Epub 2015 May 8. PMID: 25956158; PMCID: PMC4504770

27. Qiu J, Sun M, Wang Y, Chen B. Identification and validation of an individualized autophagy-clinical prognostic index in gastric cancer patients. Cancer Cell Int. 2020 May 20;20:178. doi: 10.1186/s12935-020-01267-y. PMID: 32477008; PMCID: PMC7240997.

28. Eslami M, Yousefi B, Kokhaei P, Arabkari V, Ghasemian A. Current information on the association of Helicobacter pylori with autophagy and gastric cancer. J Cell Physiol. 2019 Feb 19. doi: 10.1002/jcp.28279. Epub ahead of print. PMID: 30784066.

29. De Re V. Molecular Features Distinguish Gastric Cancer Subtypes. Int J Mol Sci. 2018 Oct 11;19(10):3121. doi: 10.3390/ijms19103121. PMID: 30314372; PMCID: PMC6213039.

30. Matsuoka T, Yashiro M. Biomarkers of gastric cancer: Current topics and future perspective. World J Gastroenterol. 2018 Jul 14;24(26):2818-2832. doi: 10.3748/wjg.v24.i26.2818. PMID: 30018477; PMCID: PMC6048430. 
31. Johnston FM, Beckman M. Updates on Management of Gastric Cancer. Curr Oncol Rep. 2019 Jun 24;21(8):67. doi: 10.1007/s11912-019-0820-4. PMID: 31236716.

32. Machlowska J, Maciejewski R, Sitarz R. The Pattern of Signatures in Gastric Cancer Prognosis. Int J Mol Sci. 2018 Jun 4;19(6):1658. doi: 10.3390/ijms19061658. PMID: 29867026; PMCID:

PMC6032410.

\section{Tables}

\section{Table 1}

LC3B, mTOR, AMPK expression, and LC3B protein content in GCs after the NACT depending on tumor size and regional lymph node involvement

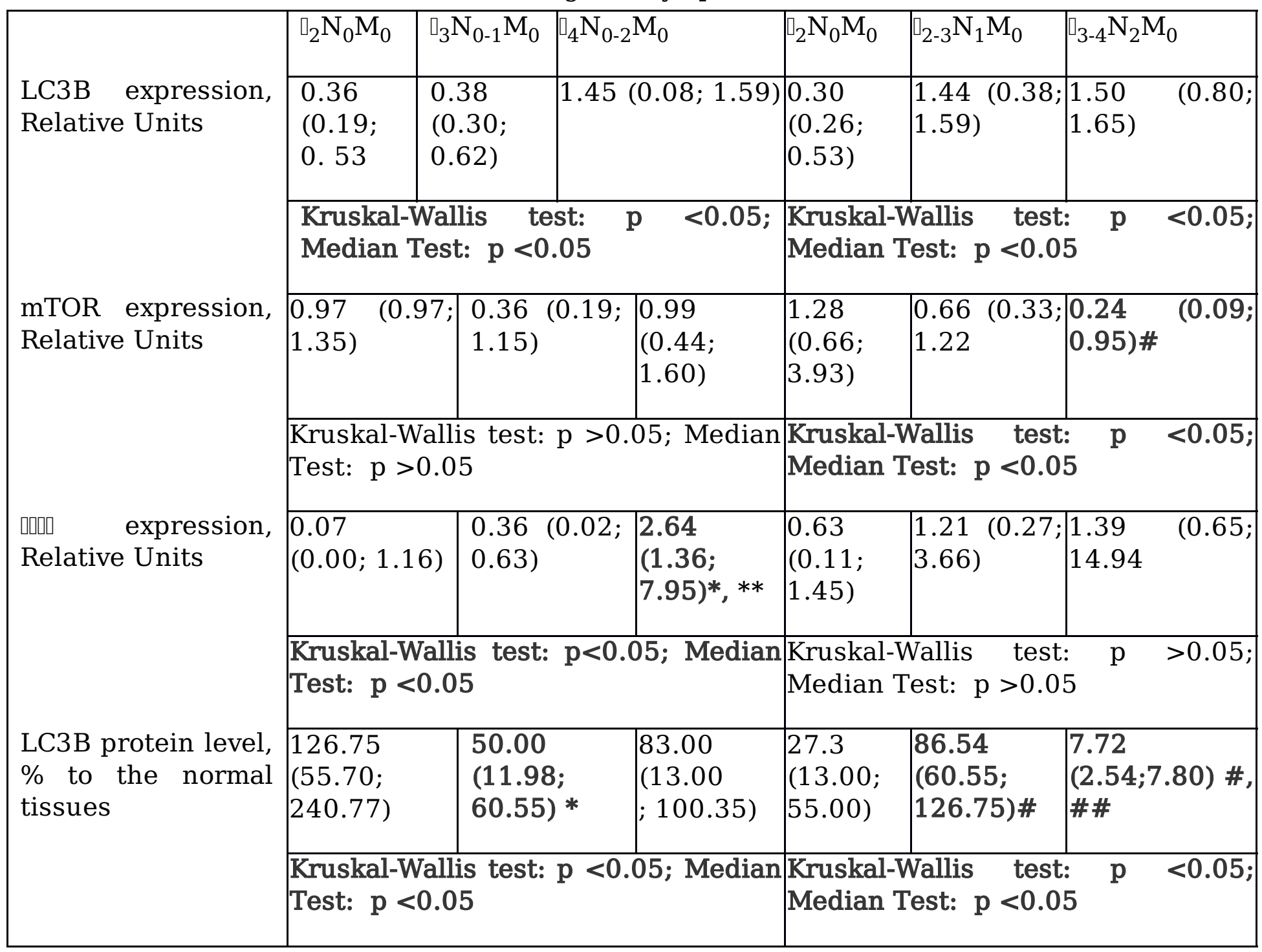

Note: * - the significance of differences in comparison with patients with tumor size $\square_{2} N_{0} M_{0}, p$ $<0.05$; ${ }^{* *}$ - the significance of differences in comparison with patients with tumor size $\square_{3} \mathrm{~N}_{0} \mathrm{M}_{0}, \mathrm{p}<0.05$; \# - the significance of the differences compared with patients with the 
stage of the disease $\square_{2} N_{0} M_{0}, p<0.05$; \#\# - the significance of differences compared with patients with the stage of the disease $\square_{2-3} \mathrm{~N}_{1} \mathrm{M}_{0}, \mathrm{p}<0.05$;

Table 2

LC3B, mTOR, AMPK expression, and LC3B protein content in GCs depending on the grade and the signet ring cell detection

\begin{tabular}{|c|c|c|c|c|}
\hline & $\begin{array}{l}\text { High- } \\
\text { differentiated } \\
\text { adenocarcinoma }\end{array}$ & $\begin{array}{l}\text { Moderataly- } \\
\text { differentiated } \\
\text { adenocarcinoma }\end{array}$ & $\begin{array}{l}\text { Low- } \\
\text { differentiated } \\
\text { adenocarcinoma }\end{array}$ & $\begin{array}{l}\text { Signet ring } \\
\text { cell } \\
\text { carcinoma }\end{array}$ \\
\hline \multirow[t]{2}{*}{$\begin{array}{l}\text { LC3B expression, } \\
\text { Relative Units }\end{array}$} & $1.45(1.20 ; 1.65)$ & $0.53(0.32 ; 0.76)$ & $1.44(1.19 ; 3.80)$ & $\begin{array}{l}0.17 \\
0.26) *\end{array}$ \\
\hline & \multicolumn{4}{|c|}{ Kruskal-Wallis test: $\mathrm{p}<0.05$; Median Test: $\mathrm{p}<0.05$} \\
\hline \multirow[t]{2}{*}{$\begin{array}{l}\text { mTOR expression, } \\
\text { Relative Units }\end{array}$} & $0.64(0.35 ; 0.85)$ & $3.93(2.89 ; 3.99)$ & $0.97(0.19 ; 1.60)$ & $\begin{array}{ll}0.58 & (0.20 ; \\
3.61) & \end{array}$ \\
\hline & \multicolumn{4}{|c|}{ Kruskal-Wallis test: $\mathrm{p}>0.05$; Median Test: $\mathrm{p}>0.05$} \\
\hline \multirow[t]{2}{*}{$\begin{array}{l}\text { expression, } \\
\text { Relative Units }\end{array}$} & $0.11(0.89 ; 0.15)$ & $1.16(1.00 ; 1.20)$ & $1.01(0.02 ; 4.06)$ & $\begin{array}{ll}0.88 & (0.45 \\
1.38) & \end{array}$ \\
\hline & \multicolumn{4}{|c|}{ Kruskal-Wallis test: $\mathrm{p}>0.05$; Median Test: $\mathrm{p}>0.05$} \\
\hline \multirow[t]{2}{*}{$\begin{array}{l}\text { LC3B protein level, } \\
\% \text { to the normal } \\
\text { tissues }\end{array}$} & $\begin{array}{ll}52.50 & (32.50 ; \\
86.70) & \end{array}$ & $35.70(15.70 ; 55.70)$ & \begin{tabular}{|l|}
83.00 \\
$126.70)$
\end{tabular} & $\begin{array}{l}17.50(7.72 \\
27.30) *\end{array}$ \\
\hline & \multicolumn{4}{|c|}{ Kruskal-Wallis test: $\mathrm{p}>0.05$; Median Test: $\mathrm{p}>0.05$} \\
\hline
\end{tabular}

Note: * - the significance of differences in comparison with patients with low-differentiated cancers, $\mathrm{p}<0.05$;

Table 3

Expression of mTOR and AMPK in gastric tumor tissue depending on the effectiveness of anticancer therapy 


\begin{tabular}{|c|c|c|c|c|}
\hline $\begin{array}{ll}\text { Indicator, } & \text { Relative } \\
\text { Units. } & \end{array}$ & $\begin{array}{l}\text { Complete } \\
\text { response }\end{array}$ & $\begin{array}{l}\text { Partial } \\
\text { response }\end{array}$ & Stable disease & $\begin{array}{l}\text { Progressive } \\
\text { disease }\end{array}$ \\
\hline \multirow[t]{2}{*}{ mTOR } & $\begin{array}{l}8.11 \\
12.30)\end{array}$ & $\begin{array}{ll}0.64 & (0.13 ; \\
0.99 * & \end{array}$ & $\begin{array}{l}0.69 \\
1.46) *\end{array}$ & $0.75(0.22 ; 1.28)^{*}$ \\
\hline & \multicolumn{4}{|c|}{ Kruskal-Wallis test: $\mathrm{p}<0.05$; Median Test: $\mathrm{p}<0.05$} \\
\hline \multirow[t]{2}{*}{ पस्पा } & (1.16; & (0.11; & $\begin{array}{l}1.13 \\
2.16)\end{array}$ & $\mid \begin{array}{l}5.36 \\
7.95) * *\end{array}$ \\
\hline & \multicolumn{4}{|c|}{ Kruskal-Wallis test: $\mathrm{p}<0,05$; Median Test: $\mathrm{p}<0,05$} \\
\hline
\end{tabular}

Note: * - significance of differences in comparison with patients with complete response, $\mathrm{p}$ $<0.05$; ** - the significance of differences in comparison with patients with partial response, $\mathrm{p}$ $<0.05$;

Figures 

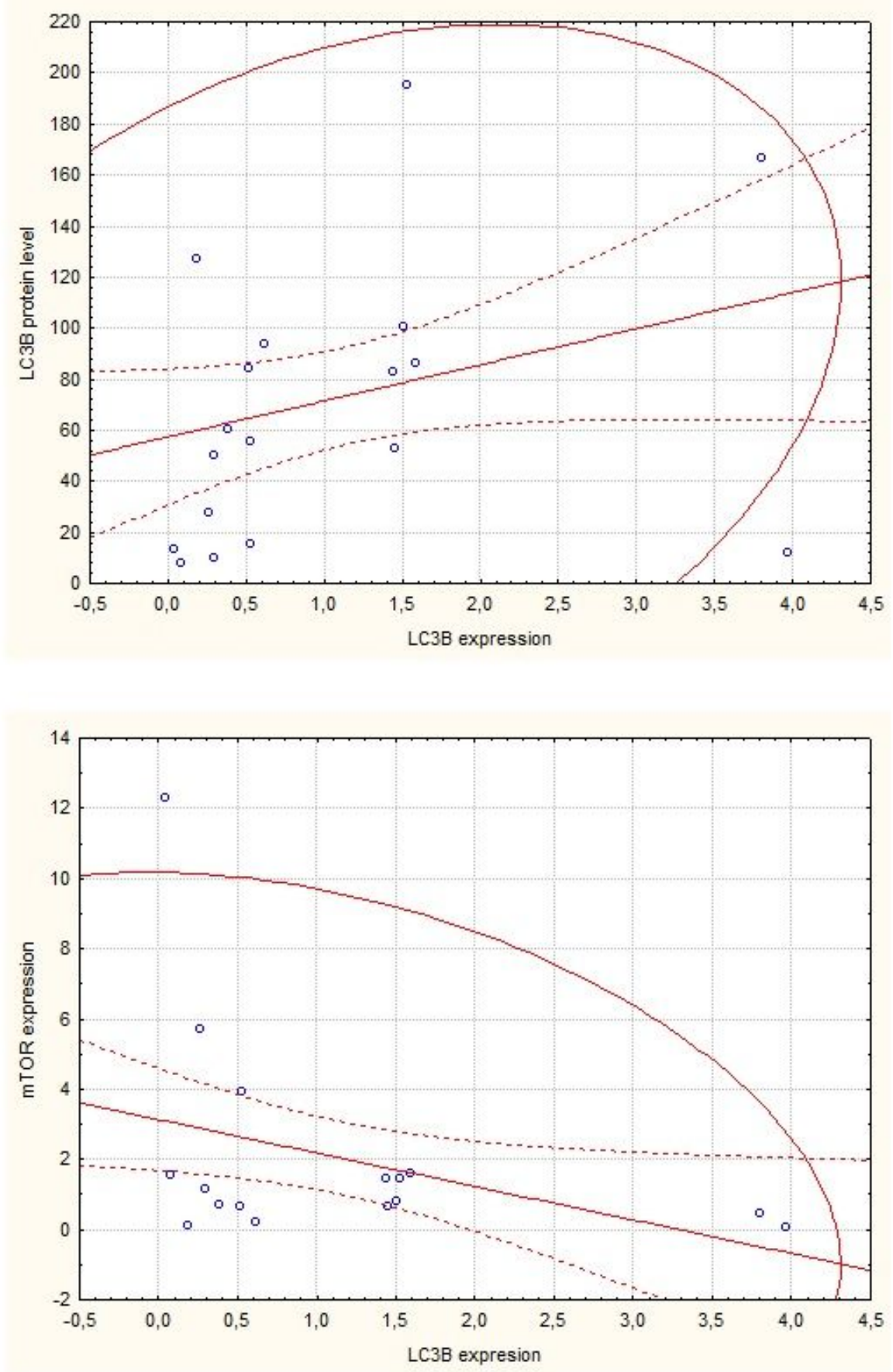

\section{Figure 1}

Scatter plots between the LC3B expression and corresponding protein level (A) and mTOR expression (B); Note: Corresponding protein levels accompany increased LC3B expression. In this case, mTOR is inhibited, which is probably associated with resistance to NACT. 


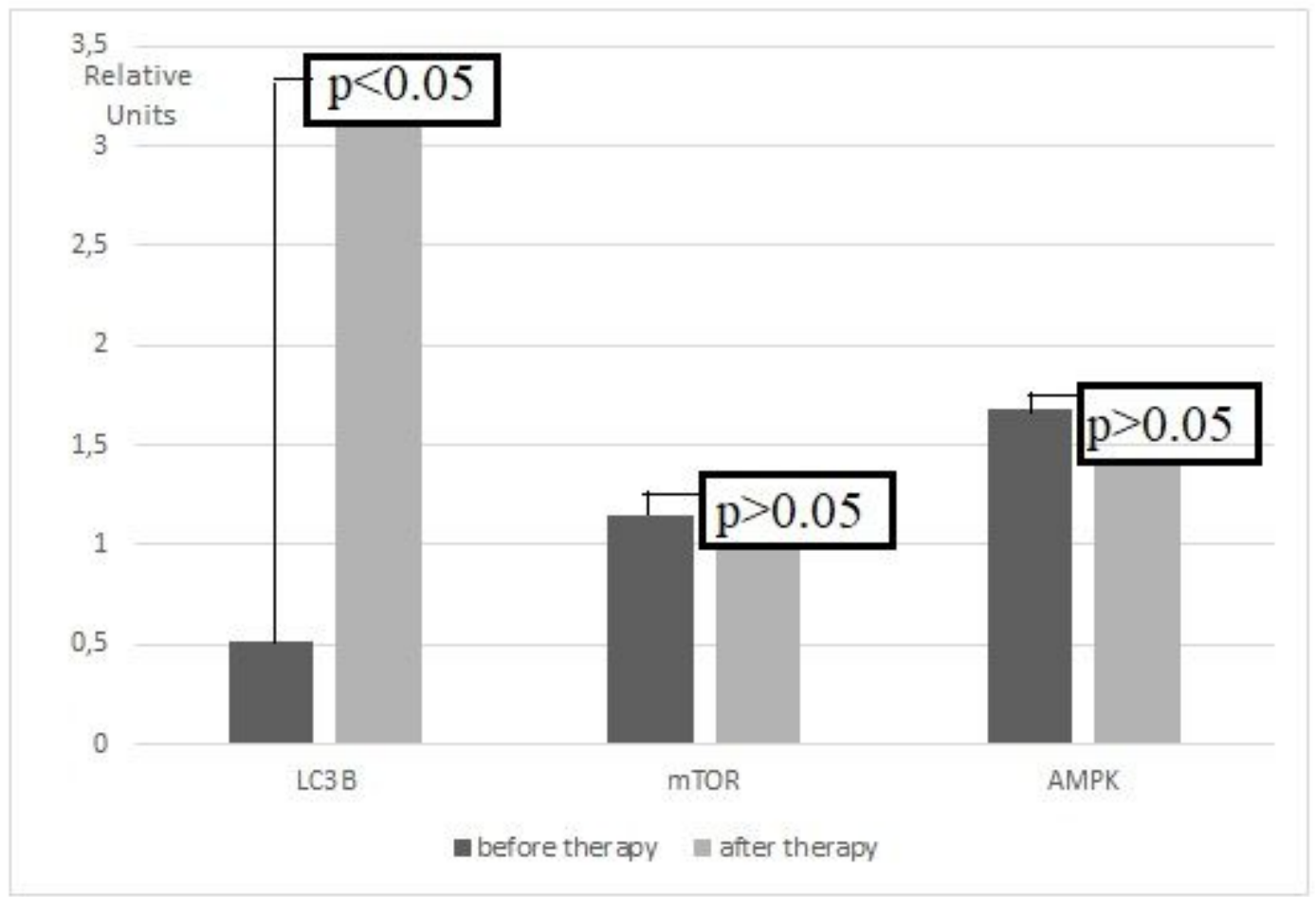

Figure 2

Expression of LC3B, mTOR, AMPK in gastric tumor tissue before and after NACT. Note: An increase in LC3B mRNA level was revealed during therapy with the FLOT regimen in patients with gastric cancer. 

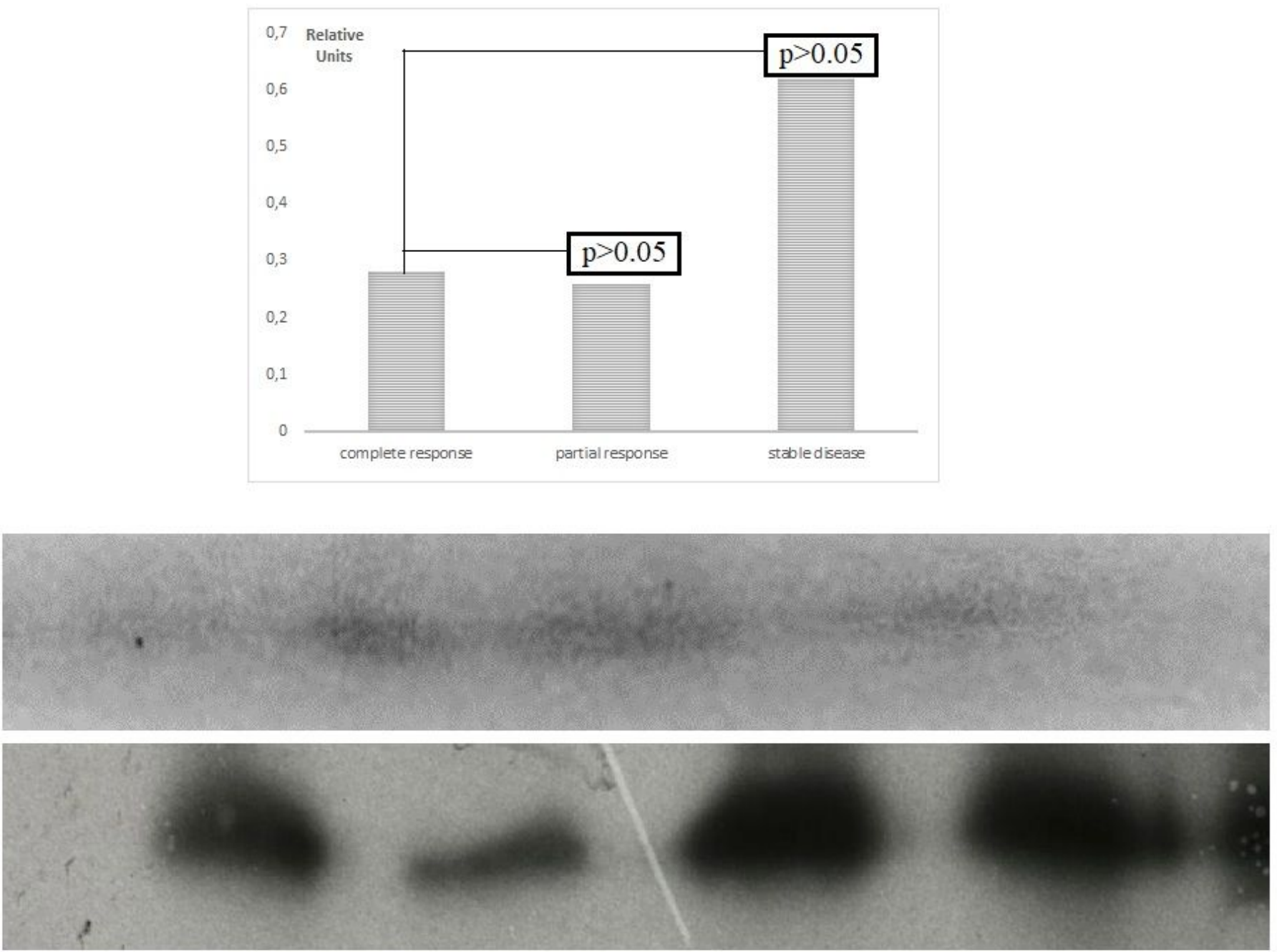

\section{Figure 3}

Expression and content of LC3B protein in gastric cancer tissue versus therapy efficacy. Note: A Expression of LC3B in gastric cancer tissue depending on The level of the indicator is not related to the effect of therapy: Kruskal-Wallis test: $p<0.05$; Median Test: $p>0.05$; $B$ - Western blotting of LC3B protein in GC (LC3B protein, 14kDa; actin, $29 \mathrm{kDa})$; C- protein level in\% relative to unchanged tissue $(100 \%)$ in the tissue of patients after NACT, depending on the effectiveness of therapy. The LC3B protein content is associated with the treatment effect: Kruskal-Wallis test: $p<0.05$; Median Test: $p<0.05$ 